\section{Tropical Journal of Pathology and Microbiology}

2020 Volume 6 Number 7 September-October

\title{
Evaluation of pre-donation anxiety and attitude of blood donors and its effect on blood pressure and pulse rate
}

\author{
Bhuyan G. ${ }^{1 *}$, Rabha A. ${ }^{2}$, Tirkey R. ${ }^{3}$, Ranga S. ${ }^{4}$ \\ DOI: https://doi.org/10.17511/jopm.2020.i07.06 \\ 1* Geet Bhuyan, Senior Resident, Department of Pathology, Vardhman Mahavir Medical College and Safdarjung Hospital, New Delhi, India. \\ 2 Anjumoni Rabha, Registrar, Department of Psychiatry, Jorhat Medical College, Assam, India. \\ 3 Rekha Tirkey, Medical Officer, Department of Blood Bank, Vardhman Mahavir Medical College and Safdarjung Hospital, New Delhi, India. \\ ${ }^{4}$ Sunil Ranga, Professor and Head, Department of Pathology, Vardhman Mahavir Medical College and Safdarjung Hospital, New Delhi, India.
}

Background: Previous negative experiences (NEs) during the process of blood donation can result in increased stress and is indicated by blood pressure and pulse rate, at a subsequent donation. The present study investigated the effect of attitude and anxiety in $1^{\text {st }}$ time and regular blood donors with or without any previous NE on the pre-donation blood pressure and pulse rate. Materials and methods: Pre-donation blood pressure and pulse rate in $1^{\text {st }}$ time and regular donors were measured. The attitude and anxiety were evaluated using a questionnaire and the relationship with a previous NE was assessed. Its effect on the blood pressure and pulse rate was subsequently evaluated. The study was a between-subjects, observational design. Results: Of the total 200 donors, 165 were males. 54 donors showed signs of anxiety whereas 33 donors had a previous NE. 11 donors (22.44\%) who had a previous negative experience showed raised blood pressure whereas 9 donors (18.36\%) with a previous negative experience showed a raised pulse rate. Both effective $(-0.293)$ and cognitive (-0.0159) attitudes were negatively correlated with anxiety and were found to be statistically significant. Conclusion: No significant association was seen in a donor who experienced a negative experience in a previous visit with raised pre-donation blood pressure however, was significantly associated with a raised pulse rate. Moreover, anxiety and increased blood pressure, and increased pulse rate were assessed in first-time donors and it was seen that first-time donors especially showed raised blood pressure and pulse rate.

Keywords: Pre donation anxiety, Blood donor, Attitude, Anxiety, Blood pressure, Pulse rate

Corresponding Author

Geet Bhuyan, Senior Resident, Department of Pathology, Vardhman Mahavir Medical College and Safdarjung Hospital, New Delhi, India. Email: geetbhuyan.aiims@gmail.com
How to Cite this Article

Bhuyan G, Rabha A, Tirkey R, Ranga S. Evaluation of pre-donation anxiety and attitude of blood donors and its effect on blood pressure and pulse rate. Trop J Pathol Microbiol. 2020;6(7):437-442. Available From

https://pathology.medresearch.in/index.php/jopm/ar ticle/view/482
To Browse

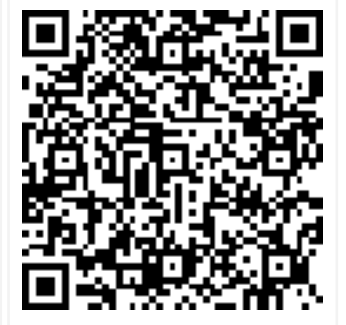

Manuscript Received 2020-09-24

Conflict of Interest No
Review Round 1 2020-10-04

Funding

$\mathrm{Nil}$
Review Round 2 2020-10-12

Ethical Approval Yes
Review Round 3

Plagiarism X-checker $4 \%$
Accepted 2020-10-20

(c) 2020 by Geet Bhuyan, Anjumoni Rabha, Rekha Tirkey, Sunil Ranga and Published by Siddharth Health Research and Social Welfare Society. This is an Open Access article licensed under a Creative Commons Attribution 4.0 International License https://creativecommons.org/licenses/by/4.0/ unported [CC BY 4.0]. 


\section{Introduction}

A stable blood supply is essential to health care services but aging populations are likely to reduce donor numbers in many countries $[1,2]$. Blood donation is a voluntary activity associated with beneficial effects such as feeling satisfied or being more alert as well as feeling better in general [3]. But, donating blood may rarely result in adverse blood donation events like fainting, dizziness, bruising, which can even cause donors to withdraw permanently from future blood donation $[4,5]$. France et al showed that $64 \%$ of the donors who did not experience a vasovagal reaction returned for a next donation within 1 year, while among donors who experienced light vasovagal reactions, only $40 \%$ returned for a next donation4. Newman and colleagues found that donors experiencing a vasovagal reaction decreased return rates by $34 \%$ [5]. In a recent study, it was shown that previous adverse events, unfamiliarity with blood donation, and certain ways of coping are associated with a heightened state of anxiety [6].

Hoogerwerf et al in their study found that the predonation blood pressure of donors who had a negative donation experience (e.g. vasovagal reaction, deferral) when compared with that of donors without such an event, donors had a raised systolic and diastolic blood pressure at the subsequent donation attempt7. An exaggerated cardiovascular response to acute and chronic stresses may lead to an increase in the heart rate, contractility, vasoconstriction, the level of epinephrine and norepinephrine secreted by the adrenal medulla and sympathetic nerves $[8,9]$. Bellitti et al. studied that similar to a rise in the BP, first-time blood donors also showed an increase in the pulse rate secondary to the stress-related release of cortisol hormone [10].

Different measures and techniques are being used in different blood banks around the world to reduce the stress of donors during blood donation. However, the anticipatory physiological stress in 1st time and donors with a previous adverse reaction is surprisingly overlooked. Attitude, which may be cognitive or affective, is a measure of how a donor rates the behavior in terms of importance and pleasantness of the blood donation process and is a predictor of his/her intention to donate in the future [11]. The role of trait donation anxiety in future donation and donor retention is still unclear with conflicting views.
Few studies have stated that there is no difference in intention to donate $[13,14]$, whereas others present evidence of a negative influence on the intention to donate in the future [15].

\section{Materials and methods}

Donor registration and screening were done according to the NACO guidelines for blood donor selection and blood donor deferral. The present study selected 200 donors who came for replacement donation and voluntary donation between January 2019 and December 2019 was included in this study. The selected donors were given a questionnaire before their medical check-up in the blood bank. The data used in this study is collected from the questionnaire. A complete demographic profile of all the selected donors was taken.

Donor attitude: The anxiety and attitude of the donors were assessed in the questionnaire before their medical check-up using the method described by Van Dongen et al $[15,16]$. The questionnaire collected data on the following three variables.

Cognitive attitude towards blood donation was assessed by rating three bipolar statements on a 7point Likert scale on the question "giving blood regularly the coming 2 years seems to $\mathrm{me}^{\prime \prime}$ (1) negative-positive, (2) useless - useful, (3) not worth it - worth it]. Affective attitude towards blood donation was assessed by rating three bipolar statements on a 7-point Likert scale "giving blood regularly the coming 2 years seems to $\mathrm{me}^{\prime \prime}$ (1) annoying - fun, (2) unpleasant - pleasant, (3) scary - not scary). Donation-related anxiety was assessed by rating three statements on a 7-point Likert scale on three questions, viz. (1) 'I am nervous and/or tense about blood donation', (2) 'I am afraid of needles', (3) 'I'm sometimes afraid of becoming unwell or faint at a blood donation'. It was graded from entirely disagree- entirely agree.

For each, a mean score was calculated.

Negative experiences: Any negative experience i.e. adverse events or deferral during a previous donation was assessed using the questionnaire. Items included in adverse reactions were dizziness, headache, nausea, sweating, hyperventilation, and fainting. Also, needle reactions in the form of vasovagal symptoms, needle reactions (bleeding, hematoma), fatigue, or deferral were noted. Donors replying 'yes' for any of the items was considered a negative experience and was noted. 
Blood pressure: Blood pressure was measured during the pre-donation screening while the donor is seated according to the standard operating procedure of the blood bank using a digital oscillometric BP monitor, type Omron HEM-7124 (Omron Healthcare, Lake Forrest, IL, USA). Donors with a history of hypertension who are on or off medication were excluded from the study. The radial pulse rate of the donors was also noted. BP $>140 / 90$ and pulse rate of $>100$ beats per minute was considered raised during the study.

Statistical analysis: Statistical analyses were performed with computer software (SPSS, Version 19.0, SPSS, Inc., Chicago, IL). This study used a between-subjects, observational design. On this set of donors, an independent-samples $t$-test was applied to identify differences between donors with and without a negative experience. A Chi-square test was performed to determine the statistical significance of several variables used in the study. Statistical significance was set at $P \leq 0.05$.

\section{Results}

A total of 200 donors were included in the study, predominantly males $(n=165,82.5 \%)$. The mean age of the donors was 33.9 years. A total of 80 were first-time donors whereas 120 had a history of two or more donations in the past (Table 1 ).

Table-1: Socio-demographic profile of donors.

\begin{tabular}{|c|c|}
\hline Variables & $\begin{array}{c}\text { Study Group (N=200) Mean (SD) (range)/ } \\
\text { frequency }(\%)\end{array}$ \\
\hline \multicolumn{2}{|l|}{ Parents } \\
\hline Age (in years) & $33.92(10.38)(18-60)$ \\
\hline \multicolumn{2}{|l|}{ Gender } \\
\hline Females & 35 (17.5) \\
\hline Male & $165(82.5)$ \\
\hline \multicolumn{2}{|l|}{ Education } \\
\hline$\leq 10$ th & $41(20.5)$ \\
\hline$>10$ th & $159(79.5)$ \\
\hline \multicolumn{2}{|c|}{ Occupation status } \\
\hline Unemployed & $22(43.1)$ \\
\hline Employed & $29(56.9)$ \\
\hline \multicolumn{2}{|l|}{ Type of family } \\
\hline Nuclear & 27 (52.9) \\
\hline Extended/ Joint & $24(47.1)$ \\
\hline \multicolumn{2}{|l|}{ No of donation } \\
\hline $\begin{array}{l}\text { Present } 2 \text { and } \\
\text { above }\end{array}$ & $120(60)$ \\
\hline Absent & $80(40)$ \\
\hline Blood pressure & \\
\hline
\end{tabular}

\begin{tabular}{|l|l|}
\hline $\begin{array}{l}\text { Normal } \\
\text { High }\end{array}$ & $\begin{array}{l}151(75.5) \\
49(24.5)\end{array}$ \\
\hline Pulse rate & $170(85)$ \\
\hline Normal & $30(15)$ \\
\hline High & $\begin{array}{l}33(16.5) \\
\text { Previous adverse reaction }\end{array}$ \\
\hline Yes & $167(83.5)$ \\
\hline
\end{tabular}

The donor's attitude and anxiety towards blood donation were measured from the data collected from the questionnaire. A total of 54 donors of the total $200(27 \%)$ donors showed signs of anxiety in their pre-donation assessment. Of this 54 who showed signs of anxiety, $36(66.67 \%)$ were firsttime donors whereas $18(33.33 \%)$ were regular donors.

Both effective (-0.293) and cognitive (-0.0159) attitudes were negatively correlated with anxiety and were found to be statistically significant. A total of 33 donors had a previous history of negative experience. 13 of these 33 donors showed signs of anxiety during their pre-donation assessment. This shows that a previous negative experience is associated with anxiety in donors coming for future donations.

As a part of the medical check-up, blood pressure, and pulse rate are routinely measured in donors. Blood pressure was raised in 49 donors whereas pulse rate was raised in 30 donors in total. 11 donors $(22.44 \%)$ who had a previous negative experience showed raised blood pressure in their pre-donation checkup whereas 9 donors (18.36\%) with a previous negative experience showed a raised pulse rate (Table 2 ).

The anxiety of donors during their first visit to the blood bank and its relationship with a raised blood pressure and pulse rate was evaluated. It was seen that 22 first time donors who had a raised blood pressure and 12 first time donors having a raised pulse rate was associated with a sense of anxiety in their pre-donation assessment. Thus we can understand that anxiety can influence the predonation blood pressure and pulse rate of the donors. This was especially seen in first-time donors as compared to regular donors.

Summarising the above, no significant association between previous negative experience and predonation blood pressure on a later visit was noted. However, the association between previous negative experience with pre-donation increased pulse rate was found to be statistically significant $(p<0.05)$. 
Both affective and cognitive attitudes were negatively associated with anxiety and were found to be statistically significant. A significant interaction was found between donors with a previous negative experience and anxiety in the donors coming for future blood donation. Lastly, as a part of the study, anxiety and its relationship with increased blood pressure and increased pulse rate was assessed in first-time donors and it was seen that first-time donors especially showed raised blood pressure and pulse rate during their pre-donation assessment.

Table-2: Relationship of BP and pulse rate with previous adverse.

\begin{tabular}{|c|c|c|c|c|c|}
\hline \multicolumn{6}{|c|}{ Previous adverse reaction } \\
\hline & & yes & No & Total & Chi-square test \\
\hline \multirow[t]{2}{*}{ B.P } & High & 11 & 22 & 33 & \multirow[t]{2}{*}{$1.667(0.197)$} \\
\hline & Normal & 38 & 129 & 167 & \\
\hline \multirow[t]{2}{*}{ Pulse rate } & High & 9 & 21 & 30 & \multirow[t]{2}{*}{$4.669(0.031)$} \\
\hline & Normal & 24 & 146 & 170 & \\
\hline \multirow[t]{2}{*}{ No. of donations } & 1 st & 11 & 69 & 80 & \multirow[t]{2}{*}{$0.732(0.392)$} \\
\hline & 2 or more & 22 & 98 & 120 & \\
\hline
\end{tabular}

\section{Discussion}

In this study, no effect of the donor attitude was associated with a previous negative experience and blood pressure of the donors. Only 12 donors who had a previous negative experience showed raised blood pressure in their pre-donation medical checkup. 5 of the 32 donors who had previous negative experience had a concurrent raised pre-donation blood pressure and associated anxiety.

This is in agreement with a previous study done by Hoogerwerf et al [16], who failed to find any significant relationship between pre-donation attitude with the pre-donation blood pressure of the donors. However, donors who had a previous negative experience showed signs of anxiety during their pre-donation assessment. This finding is in agreement with a previous study done by CR France et al in 2013 [14].

The relationship of pulse rate with anxiety associated with a previous negative experience was studied and it was found to be statistically significant. This is surprisingly the first article to study the relationship between the effect of anxiety on the pre-donation pulse rate in blood donors. On extensive search of PubMed / Medline, no study for the same was found. Moreover, the current study took a complete demographic and socio-economic profile of the selected donors.
41 of the 200 donors attended school up to middle school. It was seen that 9/41 donors showed signs of anxiety in their pre-donation assessment whereas in 7 donors it was associated with a raised blood pressure. It was seen that 14 / 41 donors had a raised pulse rate. This data shows that the anxiety levels were significantly raised in this group of donors.

The lower socio-economic and educational status may be negatively associated with the pre-donation anxiety of donors and this may be due to the lack of knowledge of the blood donation process and the benefits of it. This is the first article to study the level of education of donors and their relationship with pre-donation anxiety among them. However, a future study with a larger sample size may be required to verify the same.

The present study tried to find the effect of anxiety on the blood pressure and pulse rate in first-time donors and it was seen that a total of 36 donors experienced pre-donation anxiety in the present study and it was associated with a raised blood pressure in 22 of them. This was found to be statistically significant. Also, it was observed that the pulse rate was raised in 12 of these donors.

Therefore it was observed that 1st-time donors are more prone to pre-donation anxiety than experienced donors. This is in accordance with a previous study done by CR France et al in 2018 [17]. France et al found that feeling of donationrelated fear is less observed in experienced donors when compared to 1st-time donors. This donation related fear and anxiety can be due to different donation related stimuli like blood, needle, pain, or a fear of fainting.

\section{Conclusion}

In conclusion, no significant association was seen in a donor who experienced a negative experience in a previous visit with raised pre-donation blood pressure on a later visit. However, the association between a previous negative experience with predonation increased pulse rate was found to be statistically significant.

Both affective and cognitive attitudes were found to be negatively associated with anxiety and were found to be statistically significant. A significant interaction was found between donors with a previous negative experience and anxiety when they came for a future blood donation. 


\section{What does the study add to the existing knowledge}

Anxiety and its relationship with increased blood pressure and increased pulse rate were assessed in first-time donors and it was seen that first-time donors especially showed raised blood pressure and pulse rate during their pre-donation assessment.

However, these findings should be explored in future studies taking into account various other stress parameters and also stress markers like serum cortisol levels to get a better insight of the basis of these findings to minimize negative donation experiences by targeting specific interventions.

\section{Author's contributions}

Dr. Geet Bhuyan: Concept

Dr. Anjumoni Rabha: Manuscript preparation

Dr. Rekha Tirkey: Study design

Dr. Sunil Ranga: Manuscript preparation

\section{Reference}

01. Ali A, Auvinen MA, Rautonen J. The aging population poses a global challenge for blood services. Transfusion. 2009;50(3)584-588.

doi: $10.1111 /$ j.1537-2995.2009.02490.x [Crossref]

02. Greinacher A, Fendrich K, Alpen U, Hoffmann W. Impact of demographic changes on the blood supply- Mecklenburg-West Pomerania as a model region for Europe. Transfusion. 2007;47(3)395-401.

doi: $10.1111 /$ j.1537-2995.2007.01129.x [Crossref]

03. Nilsson Sojka B, Sojka P. The blood-donation experience: perceived physical, psychological and social impact of blood donation on the donor. Vox Sang. 2003;84(2)120-128.

doi: $10.1046 / j .1423-0410.2003 .00271 . x$ [Crossref]

04. France C, Rader A, Carlson B. Donors who react may not come back- Analysis of repeat donation as a function of phlebotomist ratings of vasovagal reactions. Transfus Apher Sci. 2005;33(2)99-106.

doi: 10.1016/j.transci.2005.02.005 [Crossref]
05. Newman B, Newman D, Ahmad R, Roth A. The effect of whole-blood donor adverse events on blood donor return rates. Transfusion. 2006;46(8)1374-1379.

doi: $10.1111 /$ j.1537-2995.2006.00905.x [Crossref]

06. Hoogerwerf, MD, Veldhuizen I, de Kort W, Frings-Dresen $\mathrm{M}$, Sluiter J. Factors associated with psychological and physiological stress reactions to blood donation- a systematic review of the literature. Blood Transfusion. 2015; (13)354-362.

doi: $10.2450 / 2015.0139-14$ [Crossref]

07. Hoogerwerf $M$, Veldhuizen I, van den Hurk $K$, de Kort W, Sluiter J, Frings-Dresen M. Negative experiences and predonation blood pressure at the subsequent donation in blood donors. Vox Sang. 2015;110(2)107-115.

doi: 10.1111/vox.12319 [Crossref]

08. Ulrich-Lai $Y$, Herman J. Neural regulation of endocrine and autonomic stress responses. Nat Rev Neurosci. 2009;10(6)397-409.

doi: $10.1038 / \mathrm{nrn} 2647$ [Crossref]

09. Ayada C, Toru Ü, Korkut Y. The relationship of stress and blood pressure effectors. Hippokratia. 2015;19(2)99-108.

[Crossref]

10. Bellitti $P$, Valeriano $R$, Gasperi M, Sodini $L$, Barletta D. Cortisol and heart rate changes in first-and fourth-time donors. Vox Sang. $1994 ; 67(1) 42-45$.

doi: $10.1111 /$ j.1423-0410.1994.tb05036.x [Crossref]

11. Veldhuizen I, Ferguson E, de Kort W, Donders R, Atsma $F$. Exploring the dynamics of the theory of planned behavior in the context of blood donation does donation experience make a difference?. Transfusion. 2011;51(11)24252437.

doi: $10.1111 /$ j.1537-2995.2011.03165.x [Crossref]

12. van Dongen $A$, Abraham $C$, Ruiter $R$, Veldhuizen I. The influence of adverse reactions, subjective distress, and anxiety on retention of first-time blood donors. Transfusion. 2012;53(2)337-343. doi: 10.1111/j.1537-2995.2012.03810.x [Crossref] 
13. Hoogerwerf $M$, van Dongen $A$, Middelburg $R$, Merz $E$, de Kort $W$, Frings-Dresen $M$ et al. Negative experiences and pre-donation blood pressure- the role of attitude and anxiety. Transfusion Medicine. 2016;27(2)105-113.

doi: $10.1111 /$ tme.12374 [Crossref]

14. France C, France J, Wissel M, Ditto B, Dickert $T$, Himawan L. Donor anxiety, needle pain, and syncopal reactions combine to determine retention- a path analysis of two-year donor return data. Transfusion. 2013;53(9)1992-2000. doi: 10.1111/trf.12069 [Crossref]

15. van Dongen A, Abraham C, Ruiter R, Schaalma $\mathrm{H}$, de Kort W, Dijkstra J et al. Are lapsed donors willing to resume blood donation, and what determines their motivation to do so?. Transfusion. 2011;52(6)1296-1302.

doi: 10.1111/j.1537-2995.2011.03447.x [Crossref]
16. van Dongen A, Abraham $C$, Ruiter $R$, Veldhuizen I. Does Questionnaire Distribution Promote Blood Donation?- An Investigation of QuestionBehavior Effects. Ann Behav Med. 2012;45(2)163-172.

doi: $10.1007 / \mathrm{s} 12160-012-9449-3 \quad$ [Crossref]

17. France C, France J. Fear of donation-related stimuli is reported across different levels of donation experience. Transfusion. 2017;58(1)113-120.

doi: $10.1111 /$ trf.14382 [Crossref] 